\title{
Long-term monitoring of the vegetation cover of mountain territories in the GIS for soil and landscape study of territories
}

\author{
Gulnora Djalilova ${ }^{{ }^{*}}$, Feruza Mamatkulova $^{1}$, Zamira Mamatkulova ${ }^{1}$, Dilfuza \\ Igamberdiyeva $^{2}$, and Quvonchbek Eshquvatov ${ }^{3}$ \\ ${ }^{1}$ National University of Uzbekistan, Tashkent, Uzbekistan \\ ${ }^{2}$ Tashkent State Agrarian University, Tashkent, Uzbekistan \\ ${ }^{3}$ Tashkent Institute of Irrigation and Agricultural Mechanization Engineers, Tashkent, Uzbekistan
}

\begin{abstract}
Rational use of natural resources and preservation of the environment in good conditions is the basis of the stable state of the ecosystem. Mountain soil erosion is the most common process of degradation. Soil protection from erosion is becoming a global problem in the world, and in Uzbekistan, in particular. Natural conditions of the region create a potential danger of soil erosion. The reason for its manifestation is the misuse of land, non-compliance with necessary requirements for soil protection. In most cases, it is due to the location of homesteads and crops on erosion-prone soils that poorly protect soil from erosion, improper cultivation of soils on arable land, unregulated grazing of pastures, and damage to soil protective plantations.

The climate, topography and soils can in some way create a potential danger of erosion, while the vegetation cover reduces the possibility of erosion or completely prevents it. V.V.Dokuchaev [6] has given great importance to vegetation in the problems of soil protection from erosion and a decrease in the flow of atmospheric precipitation. He wrote: "... in the early spring, and after heavy rains in the virgin steppe there are no large streams, while on old-growth fields they run in all directions, storm and foam."

A good vegetation cover sharply reduces the danger of erosion when a great amount of precipitation falls out. With high intensity of rains on slopes with a good vegetation cover, the danger of erosion may be much less than in the case of rainfalls with a small amount of precipitation and with less intensity on slopes with poor plantation or without any.
\end{abstract}

\section{Introduction}

The vegetation cover of the western spurs of the mountainous areas has many similarities with the Pamir-Alai vegetation [8]. On the territory under research, the vertical zonality of vegetation is clearly expressed. Three zones are named by the terms proposed by E.P. Korovin [7] and M.V. Kultiasov [10]: low-mountain zone (ephemeral deserts), up to 1400

\footnotetext{
* Corresponding author: gulnora_jalilova@rambler.ru
} 
$\mathrm{m}$; middle-mountain (Turanian grassland-herbaceous mountain steppes), up to1400-2000 (2100) m; high-mountain (sub-alpine - boreal and Himalayan type of meadows), $2000 \mathrm{~m}$ and higher.

Forest melioration measures in mountainous areas of Uzbekistan are of crucial erosionpreventive importance in medium-high mountains, where exist the conditions for afforestation. Eighty per cent or more of the catchment area of mud flow basins are occupied by the slopes that feed the beds with a flood of liquid and solid matter. In this regard, the afforestation of slopes takes a huge volume of forest melioration work [4].

On the foremost western slopes of the mountainous areas, directly facing the hot lowlands of the Turan Basin, the upper boundary of the low-mountain zone is higher than in the inland valleys. A small western section is occupied by low-grass ephemeral deserts forming a belt of deserts or low mountains (up to 1400-1450 m); the main part of the territory lies in the middle-mountain zone of the Turan grassland-herbaceous mountain steppes.

The basin profile is asymmetric, and the slopes of southern exposures are longer and more gently sloping than the northern ones. The latter's area is small, so the vegetation of the slopes of southern rumba determines the overall character of the zones.

Inside the zones, depending on the exposure, the slopes steepness and the nature of topsoil, there is a fairly variegated carpet of diverse plant communities, in some cases xeromorphous, in others - mesoxerophilic or mesophilic. There is fairly clear confinement of certain communities to the slopes with one or another mechanical composition of soils fine-grained, gravel or stone, bearing traces of greater or less erosion.

The composition of the flora is quite rich, but few species play a dominant role in the communities. These are, first of all, grasses: bulbous barley (Hordeum bulbosum L.), Asher wheatgrass, (Agropyron Aucheri Boiss), ground reed (Calamagrostis epigeios (L.) Roth.), cocksfoot (Dactylis glomerata L.), (Bromus inermis Leyss.), bulbous bluegrass (Poa bulbosa L.). And several ephemerals: bonfire - sharp-toothed (Bromus oxyodon Schrenk.), Danton (B.Danthoniae Irin.), (B. tectorum L.), (Taenja therum crinitum (Schreb) Nevski.), aegilops (Aegilops Triuncialis L. ), (Heteranthelium piliferum (Russ.) Hochst).

The communities of bulbous barley occupy the largest area among grass formations. They are found at an altitude of 1280-2100 $\mathrm{m}$ in different (in mechanic composition) soils, preferring mainly slopes of southern rumba. Projective coverage of vegetation is $20-80 \%$. The presence of Asher wheatgrass in barley communities is typical for fine-grained areas [5].

Smaller areas are occupied by the communities of Asher wheatgrass, distributed at an altitude of $1300-1900 \mathrm{~m}$; the projective coverage is $20-100 \%$. They often spread to the northern slopes, creating their meadow and steppe groupings.

To develop effective measures to prevent soil erosion occurring in mountain areas of Uzbekistan, special studies are required that would reveal the essence of this process in quantitative and qualitative terms. This land is characterized by strong surface division, significant variations in the thickness of soil formation and soil cover, and botanical composition of vegetation and other factors that practically do not manifest themselves on various plains or slightly wavy areas [9].

The possibilities of remote sensing data application have now expanded considerably. Of course, this is due to open access to a variety of remote sensing data obtained with different sensors and constant "up-grading" of software for their processing.

For medium-scale soil-landscape mapping, the most widely used is the data from Landsat sensors of multispectral imagery, since the images from these satellites can be received every two weeks. At the same time, they could be taken of the area of interest. The difference in the images of the modern generation, an increase in the number of spectral 
channels (the number of channels has reached 11) makes it possible to decode various natural objects with high accuracy [1].

The complexity of decoding, classification, and systematization of natural objects is because the landscape, by its characteristic features, is a complex formation, which includes the elements and components of a diverse and heterogeneous nature.

The creation of soil-landscape studies begins with the analysis of the relief, since the relief is a factor of landscape formation, and its impact is expressed through hypsometry, slope elements and slope exposures, the combination of which leads to the formation of landscape locations [11]. For the mountain territory of Uzbekistan, remote sensing data based on ArcGIS is used; [9]. a digital relief model (DRM) of the area under study is developed. DRM allows one to isolate the high-altitude zones of the research object and draw up maps reflecting the character of slopes (exposure and steepness).

\section{Materials and Methods}

Analysis of high-rise terrain points and the parameters characterizing the slopes have shown that the tendency to increase the steepness of the slopes with increasing altitude is quite visible on the territory of the object under research. When compiling a soil-landscape map, it is necessary to classify the vegetation cover. Traditionally, this was carried out in field research, but at the moment, with the onset of the intensive introduction of modern technologies, this task is solved much faster and more accurately based on the processing of remote sensing data.

In soil-landscape mapping, vegetation should be classified considering the qualityspecies composition and quantity characteristics - phytomass reserves. When classifying the quality characteristics of vegetation, it is necessary to use its spectral reflective properties in individual channels and determine the classification of quantity characteristics of vegetation, for example, wood, shrub and herbaceous vegetation; it is necessary to use a variety of vegetation indexes.

At present, there are more than 150 options of vegetation index calculations based on the two most stable sections of the spectral reflectivity curve of plants that do not depend on other factors [14]. RED- 0.62-0.75 $\mu \mathrm{m}$ - the red zone of the spectrum is the maximum absorption of solar radiation by chlorophyll, and NIR-0.75-1.3 $\mu \mathrm{m}$ is the near infrared zone - the maximum energy reflection by the cellular structure of the leaves. This indicates a high photosynthetic activity associated with a large phytomass of vegetation, leading to lower values of reflection coefficients in the red zone of the spectrum and greater values in the near infrared zone.

The ratio of these two indicators makes it possible to clearly separate the vegetation cover from other natural objects. The best known vegetation index is the normalized difference vegetation index - NDVI (Normalized Difference Vegetation Index), based on the reflection ratio in the red and near infrared spectral zones. Its values range from -1 to +1 . Contrary to this feature of reflection in the NIR-RED spectral regions, natural objects not related to vegetation cover will have a fixed value of the NDVI, which allows using this parameter for their identification.

NDVI being an artificial dimensionless indicator is intended primarily to measure vegetation's ecological and climatic characteristics and determine the parameters of humidity and organic saturation of the soil, evapotranspiration. The dependence between these parameters and the NDVI is usually not direct and is related to the features of the studied area, its climatic and ecological characteristics; besides, it is often necessary to consider the time division of the studied characteristic and the response of NDVI [13]. Due to the relative simplicity of computing the NDVI, it is widely used for thematic mapping, 
including the creation of soil-landscape maps [12]. It is the spectral index of this type that is associated with such a landscape-geophysical indicator as phytomass reserves; especially in mountainous areas where there are local physical-geographical conditions: absolute altitude, exposure and steepness of the slopes on which the flux of solar radiation and the thermal regime depend, as well as the position for the predominant transfer of air masses. It is necessary to consider that in the mountains, it is customary to distinguish solar and circulation slopes on which plant communities of different types with different phytomass reserves are formed. As is known, phytomass is an indicator of in-landscape conditions and is a good criterion for isolating large contours (rank type) of landscapes.

\section{Results and Discussion}

The object of research is the mountain areas. To calculate spectral indices, summer photographs of the research object taken in June 1990 and 2016 were chosen, since at this time of year, the vegetation is in the active vegetation phase. Preliminary processing of multispectral images of the Landsat series (geometric, thermal and atmospheric corrections) (Figs. 1, 2), and the process of calculation of spectral indices were carried out using the ENVI 5.3 program.

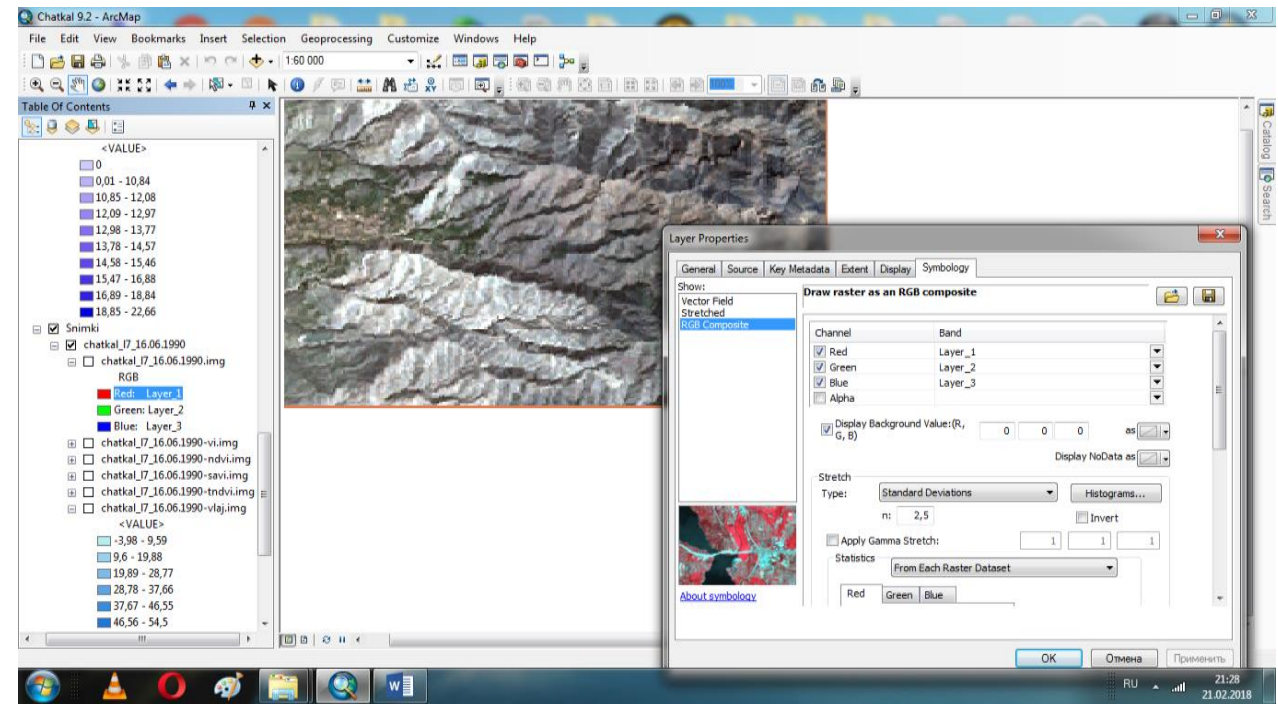

Fig.1. Satellite image of Landsat (1990, June 16) 


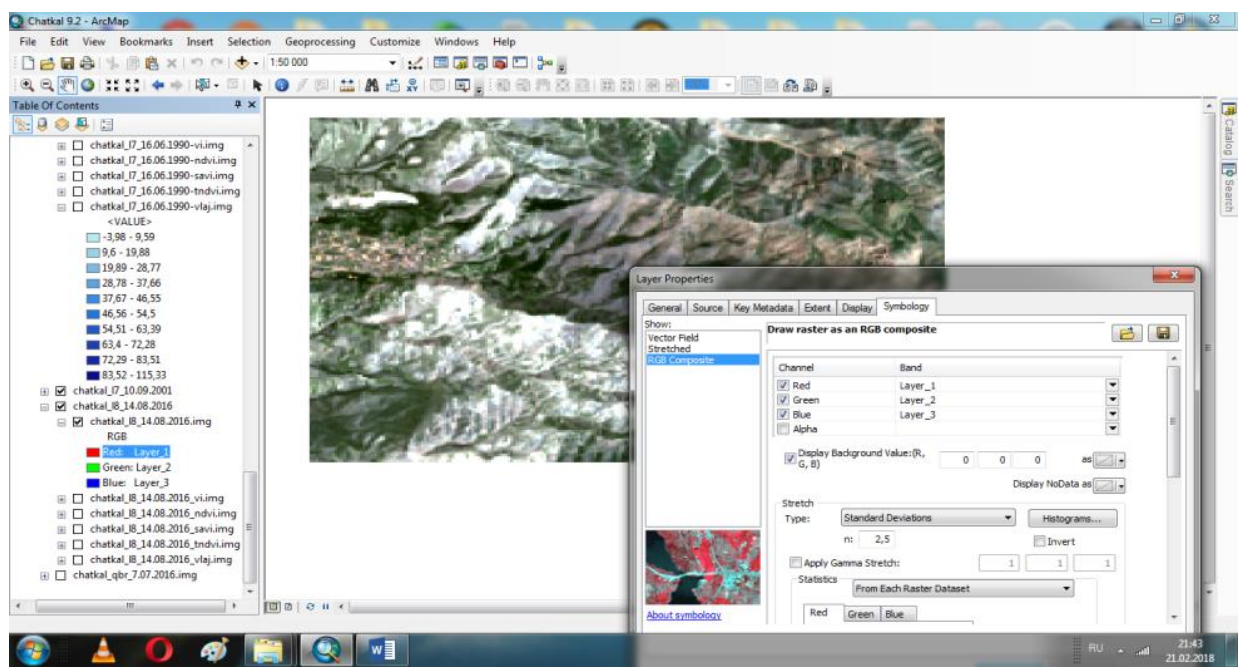

Fig.2. Satellite image of Landsat (2016, June 16)

These maps aim to assess the degree of disturbance in the vegetation cover and monitor the dynamics of vegetation cover dynamics over the last 26 years (between 1990 and 2016).

As mentioned above, the stronger the process of photosynthesis, related to increased health and density of vegetation (i.e., approaching the state of an undisturbed ecosystem), the greater the percentage of reflected radiation in the infrared region, that is, the greater the value of the NDVI (Figures 3and 4). This makes it possible to determine the quality and type of vegetation cover by analyzing the NDVI. A definite empirical correspondence between the value of the NDVI and the type of topsoil (including the type and quality of the vegetation cover) is presented in Table 1 [http://wiki.gislab.ru/w/DSD].

Table 1. Type of cover - value of the NDVI

\begin{tabular}{|c|c|}
\hline NDVI & Type of cover \\
\hline $0.8-1.0$ & $\begin{array}{c}\text { Very powerful, dense vegetation (tropical or broad- } \\
\text { leaved healthy forest) }\end{array}$ \\
\hline $0.67-0.8$ & Powerful, dense vegetation (forest) \\
\hline $0.4-0.5$ & Scanty and sparse tree vegetation \\
\hline $0.2-0.4$ & Shrubs and pastures \\
\hline $0.09-0.2$ & Open soil \\
\hline$-0.1-0.1$ & Rock mass, sand, snow \\
\hline$-0.42--0.33$ & Water object \\
\hline$-0.55 . .-0.5$ & Anthropogenic cover (asphalt, concrete) \\
\hline 0 & Cloud image \\
\hline
\end{tabular}

The construction of the NDVI by Landsat remote image allows assessing the type and state (degree of disturbance) of vegetation cover, including the forest cover at the date of the survey. Comparison of maps of the NDVI for different years makes it possible to estimate the dynamics of changing the state (to the best or the worst) of vegetation cover in the period under consideration [3]. Below an analysis of the NDVI value for the research object is given. 


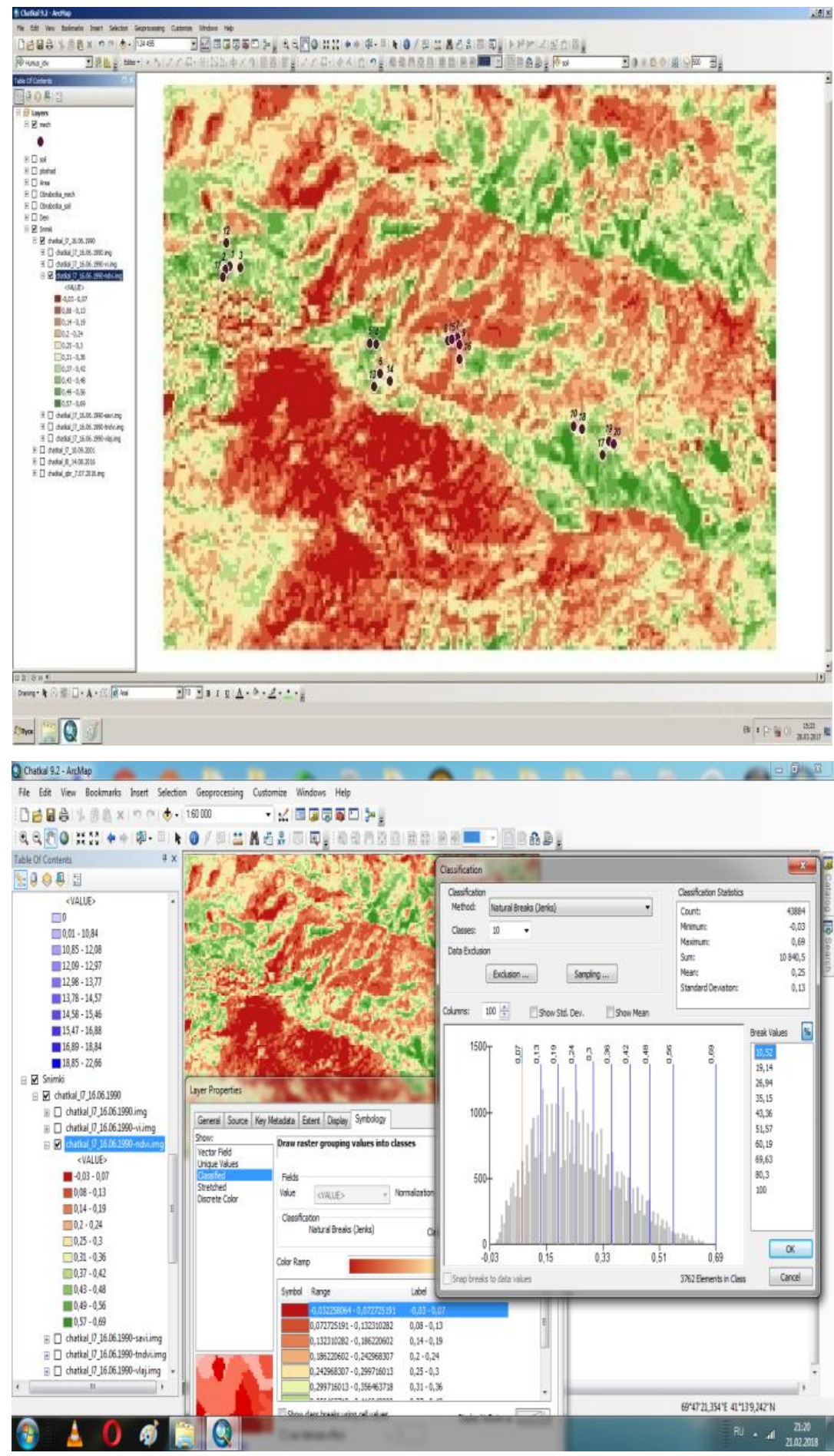

Fig. 3. Map of distribution of NDVI (1990) 

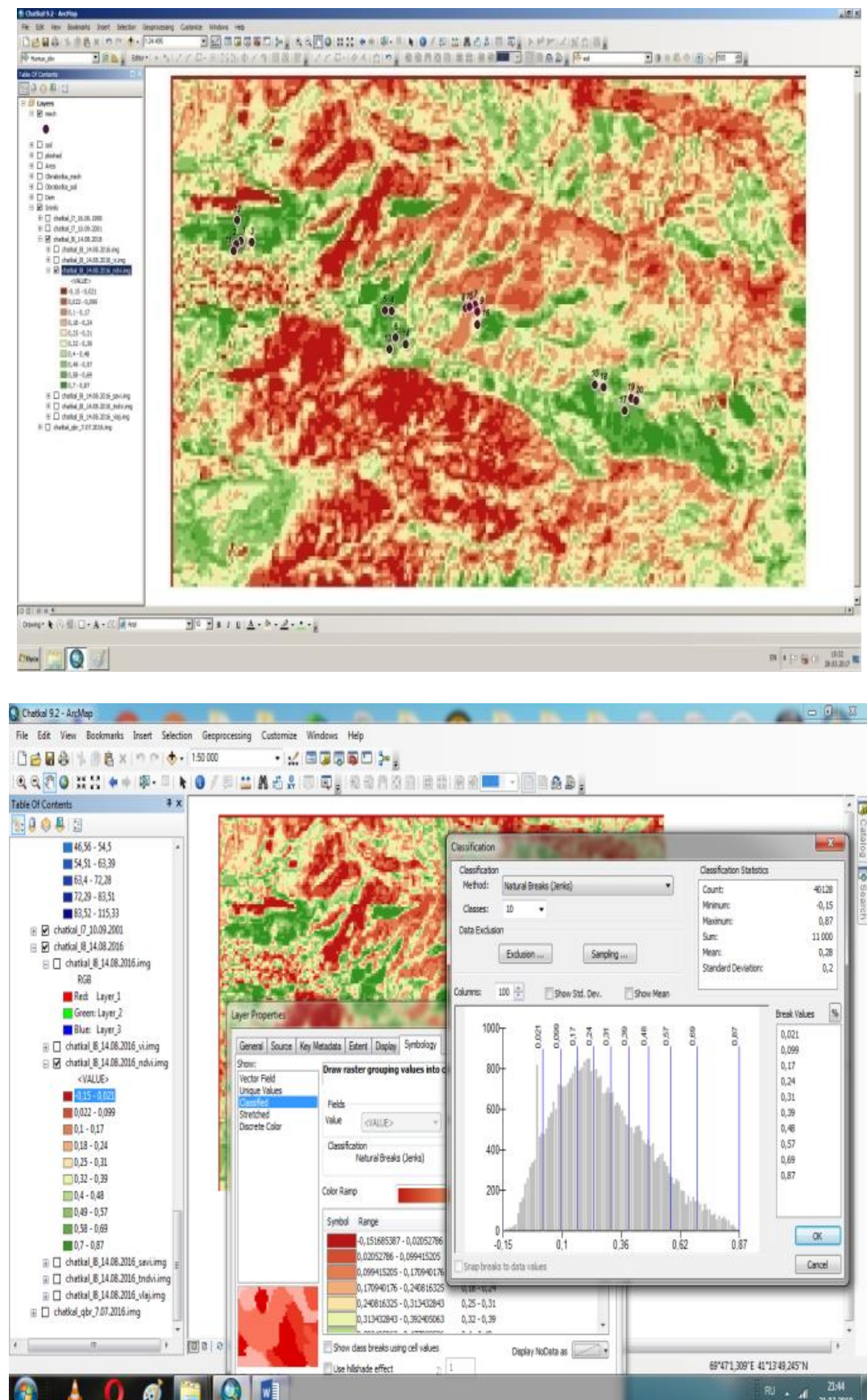

Fig. 4. Map of distribution of NDVI (2016)

Values of the NDVI within $\mathbf{0 . 1 5 - 0 . 0 2 1}$ are confined primarily to high mountains, 3000 $\mathrm{m}$ and higher, that is, in the upper altitude range of high-mountain meadow landscapes. Here, the greatest areas are occupied by high-mountain subnival complexes, where the continuous vegetation cover is practically absent, and individual fragments of meadow vegetation are represented by spots. Natural complexes characterized by low values of the 
NDVI are found in the lower tier of mountains, too: as in the highlands, these are the sites practically devoid of vegetation due to extremely low moisture content, as well as an anthropogenic influence (overgrazing). The area of such land was $8.5 \%$ in 1990 and $9.1 \%$ in 2016.

Values of the NDVI within 0,022-0,099 refer to open soil, herbaceous and shrubby vegetation, characteristic for $2500 \mathrm{~m}$ and lower, which corresponds to different vegetation options of grassy and shrubby vegetation type. However, the same values of the NDVI are characteristic for the foothill part, where they are similar to areas with steppe and semidesert vegetation, widely represented within the territory. Along with herbaceous cenosis, there are quite large fragments of shrubs and agricultural lands (fields, vineyards and pastures). The area of such land was $13.9 \%$ in 1990, and $11.3 \%$ - in 2016 .

Values of the NDVI within 0.1-0.24 correspond to the sites with shrubby and sparse tree vegetation. In this category, there are cenoses with a certain type of vegetation and landscapes for which woody natural territorial complexes with a weak density of tree tier or low forests are more typical. This zone is a transition zone from steppe and semidesert landscapes to foothill zone; in the mid-mountains, there is a transition from mountain forest to mountain meadow vegetation. The area of such land was $30.2 \%$ in 1990 , and $-27 \%$ in 2016.

Values of the NDVI within $0.32-0.48$ are quite widespread on the site of research and are typical for landscapes with shrub and sparse-tree character of the vegetation. This type of landscape is located and confined mainly to the solar slopes; it is also found in extended sections of river valleys. Within this type of landscapes, one subtype of landscapes is distinguished: mid-mountains meadow, steppe, meadow-steppe type. The area of such land was $20.5 \%$ in 1990 , and $-21.8 \%$ in 2016 .

Values of the NDVI within 0.49-0.69 correspond to the sites on which a dense vegetation cover is formed (herbaceous or shrub natural-territorial complexes). This category of the index includes natural territorial complexes related to both high-mountain meadow (subalpine) landscapes and to mountain temperate humid landscapes. In the highlands, it is mainly a thicket. The area of such land was $10.4 \%$ in 1990 , and $-14.01 \%$ in 2016.

Values of the NDVI higher than 0.7 correspond to different degrees of tree density. A single-valued relationship between the NDVI and the woody character of vegetation is noted at its values higher than 0.85 . The index in the range $0.80-0.85$, following the index gradation (Table 1) corresponds to closed (dense) tree vegetation. The area of such land is $5.5 \%$.

\section{Conclusions}

Based on data analysis, it could be concluded that for woody and shrubby vegetation, the main features of the assessment of soil protection capacity are: the closeness (density) of tree crowns and shrub belt and the state of the forest floor and topsoil cover. Vegetation is of meadow-steppe type, with many herbs and shrubs, in places - juniper, spruce, apple, individual walnut trees. A practically intact vegetative community with good soil protection ability is observed in this area. The highest percentages of projective cover are characteristic of high turf. High- and medium-resistant species are found in the grassland. Communities of this category do not need special measures for restoration (except in insignificantly insolated eroded slopes). Rational use is all they require. From what has been said above, it follows that soils distributed on shadow slopes, except for eroded differences, always have a powerful fine-grained cover, which does not contribute to the formation of surface runoff. Therefore, these sites are the best lands in mountainous areas. 
There are plant communities with insignificant signs of disturbance, such as reducing the percentage of turf cover (with a sufficiently high projective coverage) and the sites with weakly erosion-resistant species. Weak manifestation of erosion processes is observed (except for eroded insolated slopes). These lands require partial surface improvement with the regulation of use. Vegetation of this category requires partial reforestation measures aimed at increasing the closeness of crowns and the restoration of wood floor and favorable conditions for the natural renewal of wood vegetation. Naturally, all plant communities need protection, continuous reforestation measures and facilitation in natural renewal.

\section{References}

1. Bratkov V. V., Kravchenko I. V., Tuaev G. A., Ataev Z. V., Abdulzhalimov A. A. Application of Vegetation Indexes for Mapping Landscapes of the Greater Caucasus, Dagestan State Pedagogical University, Journal Natural and Exact Sciences, 10 (4), pp. 97-111, (2016)

2. Bratkov V.V. Phytomass of High-mountain Meadow Landscapes of the Greater Caucasus, Modern biogeography. Proc. of the All-Russian scientific teleconference "Biogeography at the turn of the XXI century", May 11-20, 2000 M.-Stavropol: Institute of the History of Natural Science and Technology, Russian Academy of Sciences, (2001)

3. Gafurova L.A., Djalilova G.T. Modern Approach to the Study of Erosion Processes in the Sukoksai Basin, Tashkent, Fan va Technology Publishing House, p. 158, (2017).

4. Gafurova L.A., Djalilova G.T, Ergasheva O.X., Kadirova D.A. Measures on erosionpreventive forest melioration in mountain areas of Uzbekistan. JCR, 7(2), pp. 283287. doi:10.31838/jcr.07.02.52, (2020)

5. Djalilova G.T., Zabirov F.M., Ananova K.K. Soil-geobotanical Survey of Mountain Territories for the Development of Effective Methods of Soil Erosion Control. Multidiscplinary scientific edition, International academy journal Web of Scholar 8 (17), Warsaw, Poland, pp. 11 -14, (2017)

6. Dokuchaev V.V. Selected papers (Our steppes before and now). Academy of Sciences of the USSR, (1949)

7. Using Remote Sensing of the Earth for the purposes of studying, preserving and restoring Nature [Electronic resource] / Earth remote sensing for environmental problems. Part 2:

8. Korovin E.P. Vegetation of Central Asia and Southern Kazakhstan, I and II editions, Tashkent, AN UzSSR, (1934).

9. F Gapparov, D Nazaraliev, Q Eshkuvatov. Assessment of Chimkurgan water reservoir sedimentation processes, IOP Conf. Series: Materials Science and Engineering 883 (012039) doi:10.1088/1757-899X/883/1/012039, (2020),

10. Kravchenko I.V., Galachieva L.A., Dzhandubaeva T.Z., Ibragimov A.D. Evaluation of Morphological Features of the Central Caucasus Relief for the Analysis of Landscape Formation // Proc. of the Dagestan State Pedagogical University. Natural and exact sciences, 3(28), pp. 92-97, (2014)

11. Kultiasov M.V. Etudes on the Formation of Vegetation of Hot Deserts and Steppes of Central Asia, Materials on the history of flora and vegetation of the USSR, 2, M.-L., SAGU Publishing, (1946).

12. Solntsev N.A. Selected Papers. The Doctrine of the Landscape. Moscow, Moscow State University Publishing, p. 383, (2001) 
13. Sochava V.B. Introduction to the Theory of Geo-systems, Novosibirsk: Science, p. 319, (1978)

14. Sutyrina, E. N. Remote Sensing of the Earth. Textbook. Irkutsk: IGU Publishing, p. $165,(2013)$

15. Cherepanov A.S., Druzhinina E.G. Vegetation Indices, Geomatics, 2, pp. 98-102, (2011) 